\title{
Efficacy of sugammadex in the prevention of postoperative residual curarisation and related complications in patients over 65 years of age undergoing general anaesthesia.
}

\section{Piotr Pietraszewski}

Kopernik Provincional Multispeciality Centre Oncology and Traumatology in Lodz

Tomasz Gaszynski ( $\nabla$ tomasz.gaszynski@umed.lodz.pl )

Medical University of Lodz, Poland https://orcid.org/0000-0001-5250-3978

\section{Research article}

Keywords: PACU - postanaesthesia care unit, PORC - postoperative residual curarisation, POCD postoperative cognitive dysfunction, TOF - train of four, PPC - postoperative pulmonary complications, NMBD - neuromuscular blocking drug

Posted Date: February 11th, 2020

DOl: https://doi.org/10.21203/rs.2.23131/v1

License: (c) (1) This work is licensed under a Creative Commons Attribution 4.0 International License.

Read Full License 


\section{Abstract}

Background. Neuromuscular blocking drugs have contributed to advances in anaesthesiology. The first agent blocking neuromuscular transmission was curare. Alarming respiratory complications in patients recovering from anaesthesia were reported from the very beginning of curare use. The currently used nondepolarizing muscle relaxants are regarded as safe. However, postoperative residual curarisation may be associated with the risk of complications in the first few days after general anaesthesia, especially in patients older than 65 years. This study aims to investigate the effect of sugammadex on the incidence of postoperative residual curarisation, postoperative critical respiratory events, and postoperative cognitive dysfunction. Although recommended, neuromuscular monitoring is still not standard practice during general anaesthesia with the use of muscle relaxants.

Methods. Overall, 351 patients aged 65-91 years were included in the observational study. Patients were anaesthetised at the M. Kopernik Provincial Multispeciality Centre of Oncology and Traumatology in Lodz. Spirometry and MMSE (Mini-Mental State Examination) were performed in patients one day before the surgery and one day postoperatively. Neuromuscular blockade was not monitored intraoperatively. One measurement was taken during recovery from anaesthesia. Anaesthetists made a decision to administer either a dose of $2 \mathrm{mg} / \mathrm{kg}$ sugammadex (group S) or $0.05 \mathrm{mg} / \mathrm{kg}$ of neostigmine iv (group N) during recovery from anaesthesia.

Results. There were significant differences $(p<0.001)$ between the groups in postoperative TOF ratios. The percentage of patients with TOF ratios $>0.9$ was significantly higher in the $\mathrm{S}$ group than in the $\mathrm{N}$ group ( $83 \%$ vs $49 \%$ ). The incidence of critical respiratory events was significantly lower in the S group compared to the $\mathrm{N}$ group ( $7.6 \%$ vs $17 \%$ ). The study demonstrated significant differences in the postoperative scores of MMSE.

Conclusions. Sugammadex effectively prevents postoperative residual curarisation in patients over the age of 65 . It reduces the incidence of critical respiratory events in elderly patients. The study revealed a slight trend that full reversal of the neuromuscular blockade may correspond with the improvement of postoperative cognitive functions.

Trial registration: Trial ID: ISRCTN17481425 Date registered: 27/01/2020, Link: https://www.isrctn.com/ISRCTN17481425

\section{Background}

Neuromuscular blocking drugs are widely used in everyday anaesthetic practice. They are safe when used consistently with knowledge and indications by qualified medical personnel. However, the introduction of neuromuscular blocking drug (NMBD) resulted in a 6-fold increase in the rate of mortality and complications. It has been demonstrated, for example, that in 1952, 2.4 times more people died in the United Kingdom during anaesthesia than due to polio. For this reason, some researchers began to perceive anaesthesia as a serious public health problem [1]. 
Over the next 40 years, many reports were published on the relationship between the use of neuromuscular blocking drugs and the mortality associated with anaesthesia [2, 3, 4]. Although neuromuscular monitoring is strongly recommended whenever relaxants are used for general anaesthesia [5], it is still not common practice. It has been estimated that neuromuscular function monitoring is standard practice in about $5-30 \%$ of cases of general anaesthesia in Europe. In Poland, standard relaxation monitoring is used in about $2-10 \%$ of cases. The incidence of postoperative residual curarisation (PORC) is higher in elderly patients.

A prospective study by Murphy et al. investigating patients receiving rocuronium demonstrated that PORC (TOF < 0.9 ) was identified in $58 \%$ of patients aged $70-90$ years and in $30 \%$ of patients aged $18-50$ years. Hypoxemia, PORC and hospitalization time were significantly increased in elderly patients, and occurred more frequently in both groups when residual curarisation was detected [6].

Medical professionals at the postanaesthesia care unit (PACU) deal with various clinical problems, including postoperative vomiting and cardiac arrest. Respiratory failure as one of the postoperative pulmonary complications (PPC) in the immediate postoperative period is linked to the use of anaesthetics, opioids and relaxants, but may also be a consequence of surgical trauma, haemorrhage and hypothermia [7]. The reported incidence of critical respiratory events such as impaired reflexes, desaturation, ventilation disorders requiring reintubation, pulmonary oedema or pneumonia associated with anaesthesia ranges from 1.3 to $6.9 \%[7,8,9]$. Currently used nondepolarizing muscle relaxants are regarded as safe. However, PPCs related to the use of these agents have been known for several decades. They are linked with residual curarisation, otherwise known as the incomplete reversal of the neuromuscular blockade. Reportedly, the incidence of postoperative residual curarisation in the general population has been underestimated. Our studies have revealed that $30 \%$ of patients in the PACU are still under the influence of neuromuscular blocking agents. Other researchers have identified residual curarisation in $30-42 \%$ of patients from different age groups [10,11, 12]. A recent study detected critical respiratory events (or PPCs) in $7.2 \%$ of patients who received intermediate-acting NMBDs. This study also provided interesting evidence that the use of neostigmine without routine neuromuscular monitoring increases the risk of postoperative hypoxia and reintubation [13]. Unfortunately, monitoring of neuromuscular function does not reduce the incidence of PORC [14].

In elderly patients, the procedure is associated with the risk of postoperative cognitive dysfunction (POCD). This mainly concerns the deterioration of memory and executive functions related to prefrontal cortex depression, which persist for several hours to several weeks after surgery. The risk of POCD increases with age, duration of surgery and perioperative complications. It is believed that cognitive dysfunctions in the elderly are largely attributable to stress and stress-induced inflammatory response. Relevant measures taken before, during and after surgery can reduce surgery-induced stress and the harmful effects of inflammation. Pre-emptive analgesia, anti-inflammatory drugs, and beta-blockers reduce this response before surgery. Balanced anaesthesia, body temperature control and proper awakening of the patient, avoiding early postoperative complications, may prevent postoperative cognitive dysfunctions $[14,15,16]$. 


\section{Methods}

Overall, 351 patients aged 65-91 years were included in the prospective observational study. Patients were anaesthetised by different anaesthetists at the M. Kopernik Provincial Multispeciality Centre of Oncology and Traumatology in Lodz in 2015-2018. Anaesthetists made a decision to administer either sugammadex (group S) or neostigmine iv (group N). There were 195 patients in the $\mathrm{S}$ group (sugammadex), and 162 patients in the $\mathrm{N}$ group (neostigmine). The study protocol was approved by the Local Bioethical Committee of the Medical University in Lodz (RNN/704/10/KB). Trial registration: Trial ID: ISRCTN17481425 Date registered: 27/01/2020, Link: https://www.isrctn.com/ISRCTN17481425

All patients gave written informed consent to participate in the study.

The inclusion criteria were:

- Physical status ASA class IIII.

- Patients verbally responsive and maintaining logical communication, understanding and responding to commands.

- Patients without pain disabling cooperation. Patients who were not under the clear influence of narcotic analgesics, psychotropic drugs, or in deep sedation.

- Patients scheduled for elective surgery.

- Patients scheduled for general surgery, endocrinology surgery, vascular surgery, trauma surgery, urological or oncological surgery.

- Neurosurgery and thoracic surgery patients were excluded from the study due to the expected difficulty in interpreting the results.

All patients completed a questionnaire about their current health status and medical history. ASA class was determined based on this questionnaire. ASA class I-III patients were qualified for the study.

Physical examination of patients was done by an anaesthetist one day before the surgery. Arterial blood pressure and heart rate were measured. Results of blood tests (whole blood count, blood biochemistry) and electrocardiogram (ECG) were analysed. Spirometry was performed using a Spirobank device from MIR (Medical International Research) and digital disposable turbines.

Each patient, when examined by an anaesthetist one day before surgery, and in the morning within $24 \mathrm{~h}$ after surgery, had an MMSE test (Mini-Mental State Examination).

MMSE, or the Folstein test, is a sensitive and reliable 30-point questionnaire widely used in clinical and research settings to measure cognitive impairment. MMSE is also used to measure the severity and progression of cognitive dysfunctions. Following cognitive changes in an individual over time can effectively document response to treatment. The MMSE test takes 10 minutes, and does not require special training or equipment. It is suitable for the assessment of cognitive dysfunction at the patient's bedside and in the recovery room. The test consists of 30 questions, and examines orientation to time 
and place, registration, attention, calculation, recall, language, and ability to follow simple commands, including writing and drawing. Each answer is scored. The maximum total score is 30 points. Scores in the range of 27-30 points indicate normal cognition. Scores 24-26 points may indicate cognitive impairment. Scores of 19-23 points indicate mild impairment, and scores of 11-18 points indicate moderate cognitive impairment. Scores of 10 or lower indicate severe impairment.

Spirometry.

Spirometry was performed twice, after ruling out absolute contraindications such as serious ocular diseases, elevated intracranial pressure, cerebral aneurysms or abdominal aortic aneurysm, or history of cardiovascular or cerebral event a month before enrolment to the study. Spirometry was not performed in patients with chronic pulmonary diseases or those treated with ß2-mimetics, theophylline or steroids.

Spirometry was done one day before surgery and one hour after discharge from the PACU.

The principles of the procedure were explained to the patient, and then the test was done using a portable handheld spirometer (Spirobank, MIR) with digital disposable turbines.

The patient was seated, and a clip was placed on his/her nose to close the nostrils. The patient breathed calmly and held the mouthpiece with the teeth. When instructed, the patient took a deep breath in, and then exhaled as hard as he/she could. The test was repeated three times and the highest value was recorded. One measurement was taken in patients who, because of their health status and medical complaints, were unable to withstand significant effort [17].

Assessment of residual curarisation.

Neuromuscular transmission was not routinely monitored during surgery. During recovery from anaesthesia, the degree of residual neuromuscular block was measured once with a TOF-Watch SX stimulating device (Organon, Ireland). Investigators taking measurements did not know whether the patient had received sugammadex or neostigmine.

After the immobilization of the hand, the ulnar nerve was stimulated to provoke the contraction of the adductor muscle of the thumb, and the response was recorded and measured using a piezoelectric acceleration transducer. The TOF mode is the most appropriate for the monitoring of the reversal of effects induced by nondepolarizing muscle relaxants.

In the $\mathrm{N}$ group patients received neostigmine at a dose of $2 \mathrm{mg}$ preceded by a $1 \mathrm{mg}$ bolus of atropine.

In the $S$ group patients received sugammadex at a dose of $2 \mathrm{mg} / \mathrm{kg}$.

Each patient received passive oxygen therapy and was monitored for $\mathrm{SaO}_{2}$, blood pressure and heart rate.

The second measurement of neuromuscular transmission was taken within the first 10 min of the patient's stay at the PACU. On average each patient spent 60 min at the PACU. 
Assessment for critical respiratory events.

All patients were monitored for critical respiratory events when they recovered from anaesthesia, during their stay in the recovery room (PACU), and during further hospitalization. Cases of desaturation (SaO2< 90\%) and dyspnoea at the PACU were reported.

The history of the hospitalization of patients participating in the study was analyzed. Medical records were reviewed to identify patients who developed respiratory symptoms in the postoperative period, especially those requiring respiratory diagnostics, ventilation support or reintubation within 72 hours. Further days of hospitalization were analysed to identify patients with symptoms of dyspnoea and respiratory failure, with the main focus on pneumonia.

Statistical analysis

The significance level was adopted at 0.05 , and the decision was made based on the $p$-value calculated by using statistical software. Statistics with $p \geq 0.05$ were considered significant, and the zero hypothesis was accepted. Statistics with $p<0.05$ were considered not significant, and the zero hypothesis was rejected in favour of the alternative hypothesis. The set of hypotheses depended on the specific test.

Statistical analysis was done using Statistica 10.0 PL software (StatSoft, INC, USA).

Demographic Characteristics

Overall, 351 subjects were qualified for the study (159 in the $\mathrm{N}$ group and 192 in the S group). Statistics on the age and sex of patients in both groups are presented in the table. (Table 1).

Table 1

Stratification of groups by sex and age.

\begin{tabular}{|lll|}
\hline & N group & S group \\
\cline { 2 - 3 } & Number of pts & Number of pts \\
\hline Number of patients $(n)$ & 159 & 192 \\
\hline Age & & \\
\hline $65-74$ years $(n)$ & 101 & 91 \\
\hline $75-84$ years $(n)$ & 48 & 70 \\
\hline older than 84 years $(n)$ & 10 & 31 \\
\hline Sex & & \\
\hline women $(n)$ & 59 & 124 \\
\hline men $(n)$ & 100 & 68 \\
\hline
\end{tabular}


There were significant differences between the groups in terms of age $(p=0.002)$. Overall, the ratio of patients aged 75 and older was higher in the treatment group than in the $\mathrm{N}$ group ( $52 \%$ vs. $36 \%$ ). There were significant differences between the groups in terms of sex $(p<0.001)$. The ratio of women was higher in the $S$ group than in the $\mathrm{N}$ group (65\% vs. $37 \%$ ).

\section{MMSE Scores}

Preoperative scores of MMSE did not differ significantly between the groups $(p=0.059)$. It should be noted, however, that the calculated $p$-value was slightly higher than the adopted limit. Nevertheless, because of the sample size the differences between the two groups were not significant. There were significant differences between groups in postoperative MMSE scores $(p=0.0024)$.

The analysis revealed significantly higher postoperative MMSE scores in the $\mathrm{S}$ group compared to the $\mathrm{N}$ group (29.32 vs 29.06 ), potentially attributable to the effects of sugammadex. The analysis demonstrated significant differences in postoperative scores of MMSE (after the consideration of other variables). Considering the lack of differences in preoperative scores, this result implies the significant effect of sugammadex on MMSE scores (Table 2).

Table 2

Main statistics for preoperative and postoperative values of MMSE and change of values.

\begin{tabular}{|llll|}
\hline variable & statistic/group & N group & S group \\
\hline MMSE & mean (+/- SD ) & $29.28(0.69)$ & $29.41(0.56)$ \\
\cline { 2 - 4 } & median & 29 & 29 \\
\cline { 2 - 4 } & Quartile 1 - Quartile 3 & $29-30$ & $29-30$ \\
\cline { 2 - 4 } & Min - Max & $28-30$ & $28-30$ \\
MMSE & mean (+/- SD ) & $29.12(0.81)$ & $29.31(0.73)$ \\
\cline { 2 - 4 } & median & 29 & 29 \\
\cline { 2 - 4 } & Quartile 1 - Quartile 3 & $29-30$ & $29-30$ \\
\cline { 2 - 4 } & Min - Max & $26-30$ & $26-30$ \\
MMSE & mean (+/- SD ) & $-0.16(0.5)$ & $-0.1(0.55)$ \\
\cline { 2 - 3 } & median & 0 & 0 \\
\cline { 2 - 4 } & Quartile 1 - Quartile 3 & $0-0$ & $0-0$ \\
\cline { 2 - 4 } & Min - Max & $-3-2$ & $-3-2$ \\
\cline { 2 - 4 } & & &
\end{tabular}


However, these conclusions were not supported by findings from the comparison of preoperative and postoperative MMSE scores for individual patients. Further research is necessary to resolve this issue. Possibly, the size of change in individual patients was influenced by other factors not considered in the analysis.

Forced Exhaled Volume In The First Second (FEV1)

Preoperative FEV1 values did not differ significantly between the groups $(p=0.383)$. Postoperative FEV1 values did not differ significantly between the groups $(p=0.348)($ Table 3$)$.

Table 3

Main statistics for preoperative and postoperative values of FEV1 and change of values.

\begin{tabular}{|llll|}
\hline variable & statistics/group & N group & S group \\
\hline FEV1 & mean (+/- SD) & $78.53(6.66)$ & $77.93(6.22)$ \\
\cline { 2 - 4 } & median & 79 & 78 \\
\cline { 2 - 4 } & Quartile 1 - Quartile 3 & $74-83$ & $73-83$ \\
\cline { 2 - 4 } & Min - Max & $60-97$ & $62-88$ \\
\hline FEV1 & mean (+/- SD) & $73.04(6.98)$ & $72.39(5.94)$ \\
\cline { 2 - 4 } & median & 73 & 70 \\
\cline { 2 - 4 } & Quartile 1 - Quartile 3 & $70-80$ & $68-78$ \\
\cline { 2 - 4 } & Min - Max & $55-90$ & $60-84$ \\
\hline FEV1 & mean (+/- SD) & $-5.48(3.53)$ & $-5.54(2.62)$ \\
\cline { 2 - 4 } Change in the value & median & -5 & -5 \\
\cline { 2 - 4 } & Quartile 1 - Quartile 3 & $-7--4$ & $-8--4$ \\
\cline { 2 - 4 } & Min - Max & $-16-5$ & $-12-0$ \\
\cline { 2 - 4 } & &
\end{tabular}

There were no significant differences between the groups $(p=0.865)$ in the change of postoperative and preoperative FEV1 values. Firstly, the FEV1 value (both preoperative and postoperative) depends on the patient's age. Secondly, the obtained results (preoperative vs postoperative and change) were inconsistent, and the potential effect of sugammadex on FEV1 values could not be ruled out.

Forced Vital Capacity (FVC)

Preoperative values of FVC did not differ significantly between the groups $(p=0.076)$. Postoperative values of FVC did not differ significantly between the groups $(p=0.386)$. There were no significant 
differences between the groups $(p=0.234)$ in the change of postoperative and preoperative FCV values (Table 4).

Table 4

Main statistics for preoperative and postoperative values of FVC and change of values.

\begin{tabular}{|llll|}
\hline variable & statistics/group & N group & S group \\
\hline FVC & mean (+/-SD) & $83.11(6.16)$ & $81.85(6.91)$ \\
\cline { 2 - 4 } & median & 82 & 81 \\
\cline { 2 - 4 } & Quartile 1 - Quartile 3 & $78-87$ & $78-86.5$ \\
\cline { 2 - 4 } & Min - Max & $70-98$ & $63-98$ \\
\hline FVC & mean (+/-SD) & $75.19(7.4)$ & $74.5(7.53)$ \\
\cline { 2 - 4 } & median & 75 & 75 \\
\cline { 2 - 4 } & Quartile 1- Quartile 3 & $70-80$ & $70-80$ \\
\cline { 2 - 4 } & Min - Max & $40-90$ & $40-90$ \\
\hline FVC \\
Change of values & mean (+/-SD) & $-7.91(4.28)$ & $-7.35(4.49)$ \\
\cline { 2 - 4 } & median & -8 & -7 \\
\cline { 2 - 4 } & Quartile 1 - Quartile 3 & $-10--5$ & $-10--5$ \\
\cline { 2 - 4 } & Min - Max & $-38--2$ & $-38-12$ \\
\cline { 2 - 4 } & & &
\end{tabular}

There were significant differences between age groups regarding changes in FVC (after the consideration of other factors). The greatest reduction in FVC was found in patients aged 75-84 years, and the smallest reduction in the oldest patients.

FVC values reduce with age, but their decrease after surgery compared to the baseline period was significantly smaller among the oldest patients from the treatment group compared to the control group. However, because the subgroup of the oldest patients was relatively small (particularly in the control group), these conclusions should be treated with caution, and further research is required.

ASA

There were no significant differences between the groups $(p=0.280)$. The results of assessment for ASA class in both groups were comparable (Table 5). 
Table 5

Stratification of groups by the number of

patients from specific ASA classes

assessed before surgery.

\begin{tabular}{|lll|}
\hline ASA & N group & S group \\
\cline { 2 - 3 } & Number of pts & Number of pts \\
\hline I & 7 & 3 \\
\hline II & 99 & 124 \\
\hline III & 53 & 65 \\
\hline
\end{tabular}

Postoperative TOF Ratio

There were significant differences between the groups in postoperative TOF ratios $(p<0.001)$. The percentage of patients with TOF ratios $>0.9$ at PACU was significantly higher in the $\mathrm{S}$ group than in the $\mathrm{N}$ group ( $83 \%$ vs $49 \%$ ). The odds ratio calculated for TOF at PACU $>0.9$ compared to other categories is presented below. In the $\mathrm{S}$ group the probability of TOF $>0.9$ was more than 4.5 -times higher than in the $\mathrm{N}$ group [OR 4.61 (95\% Cl 2.89-7.34)].

Incidence Of Critical Respiratory Events

The incidence of critical respiratory events was significantly lower in the S group compared to the $\mathrm{N}$ group (7.6\% vs $17 \%$ ) (Table 6). The odds ratio calculated for the incidence of critical respiratory events is presented below. In the $S$ group the probability of no critical respiratory event was almost 2.5-times higher than in the $\mathrm{N}$ group [OR 2.49 (95\% $\mathrm{Cl} 1.28-4.85)$ ] (Table 6).

Table 6

Incidence of critical respiratory events in both

groups.

\begin{tabular}{|lll|}
\hline Critical respiratory events & N group & S group \\
\cline { 2 - 3 } & & \\
\hline Yes & 26 & 12 \\
\hline No & 133 & 180 \\
\hline
\end{tabular}

In the two subgroups of younger patients similar regularity was observed, i.e. the incidence of critical respiratory events was slightly lower than in the $\mathrm{N}$ group. However, in the subgroup of the oldest patients this difference was much greater. Results should be interpreted with caution because of the small size of the $\mathrm{N}$ group in this age category, and further research is necessary to obtain data supporting these conclusions. 
In the first age group (65-74 years) there was no significant difference in the probability of critical respiratory events [OR $1.59(95 \% \mathrm{Cl} 0.66-3.83)]$.

In the second age group (75-84 years) there was no significant difference in the probability of critical respiratory events [OR $2.18(95 \% \mathrm{Cl} 0.65-7.31)]$.

In the third age group (85-88 years) there was a significant difference in the probability of critical respiratory events [OR 6.2 (95\% Cl 3.24-15.87)]. However, the confidence interval was very wide, which again implies the need for further research to verify this conclusion.

\section{Discussion}

Postoperative residual curarisation (PORC) is a risk factor for PPCs [18]. PORC is an effect of excessive blockade of presynaptic and postsynaptic receptors. Postsynaptic receptors are responsible for stimulating muscle fibres, which is why they are mainly blocked by neuromuscular blocking agents. Presynaptic receptors have a different role, and they are involved in sustaining muscle tone. PORC is frequently undiagnosed but affects about $20-88 \%$ of patients newly admitted to the PACU $[19,20]$. The incidence of PPC is in the range of 1-23\% [21-26]. Several studies have demonstrated higher incidence of postoperative pulmonary complications compared to cardiovascular complications, with the highest incidence of postoperative respiratory insufficiency $[27,28,29]$. One out of five patients with PPC is expected to die within 30 days following major surgery, but only $0.2-3 \%$ of patients without symptoms of PPC $[21,22,24,25,30]$.

Reversal of neuromuscular blockade using sugammadex is associated with a lower incidence of PORC and related PPCs compared to neostigmine-induced or spontaneous recovery of neuromuscular function, even if neuromuscular function was not monitored during anaesthesia [31].

Unlike neostigmine, sugammadex in relevant doses is able to reverse the deep block induced by aminosteroids [32]. A $2 \mathrm{mg} / \mathrm{kg}$ dose of sugammadex rapidly reverses the moderate rocuronium-induced neuromuscular block (recovery of T1/T0 to 0.2 ) within 2 minutes, which is much faster compared to neostigmine [31, 32]. A deep neuromuscular block, characterised by undetectable TOF and the possibility of inducing only tetanic twitch $1-2$, is easily reversed by sugammadex at a dose of $4-8 \mathrm{mg} / \mathrm{kg}$. Neostigmine in ineffective in such cases.

The block can be reversed immediately with higher doses of sugammadex (max. $16 \mathrm{mg} / \mathrm{kg}$ ) after the administration of rocuronium $[34,35]$. This is effective in patients who cannot be intubated and ventilated.

The incidence of PORC at the PACU is much lower if sugammadex is used instead of neostigmine at the end of anaesthesia. A prospective study by Brueckmann et al. [44] reported that all 74 patients who were administered sugammadex had TOF $>0.9$ on admission to the PACU. Cammu et al. [36] examined 624 patients and identified PORC (TOF $<0.9$ ) in $15 \%$ of patients who did not receive a reversal drug and in 
$15 \%$ of patients who received neostigmine. PORC was found only in one out of 44 patients in the sugammadex group [36]. A randomized trial conducted in 2012 by Gaszyński et al. revealed that the incidence of postoperative residual curarisation was lower in patients with morbid obesity $(\mathrm{BMI}>40)$ who received sugammadex at a dose of $2 \mathrm{mg} / \mathrm{kg}$ to reverse a moderate-degree block (TOF ratio 2) compared to a reference group of patients who received $0.05 \mathrm{mg} / \mathrm{kg}$ of neostigmine [37].

Quantitative monitoring of the residual block is necessary during the use of sugammadex and neostigmine, otherwise the block may persist. An observational study by Kotake et al. revealed that TOF < 0.9 following extubation was identified in $24 \%$ of patients given neostigmine and in $4.3 \%$ of patients given sugammadex if neuromuscular function was not monitored [38]. So far, there is no hard evidence on the lower incidence of PPC after sugammadex than neostigmine. Ledowski et al. analysed data on 1444 patients (722 received sugammadex, 212 neostigmine, and in 510 the block reversed spontaneously) and reported higher incidence of postoperative nausea and vomiting (PONV) after neostigmine compared to sugammadex $(21.5$ vs $13.6 \% ; p<0.05)$. There were no differences in the length of stay at the PACU or time of hospitalization. The risk of PPC increased with the patient's age and fitness class acc. to the ASA system. Postoperative pulmonary complications were observed in patients from ASA classes III and IV and those older than 60 years who were given neostigmine or who had spontaneous reversal of the block [39].

When neuromuscular block is monitored, only patients with TOF $>0.9$ can be extubated safely without the risk of residual curarisation.

Effects of lower doses of sugammadex in preventing residual neuromuscular block have also been investigated. Schaller et al. reported that the reversal of residual block in patients who had TOF $=0.5$ required $0.22 \mathrm{mg} / \mathrm{kg}$ sugammadex and the effect was comparable to that elicited by neostigmine at a dose of $0.034 \mathrm{mg} / \mathrm{kg}$ [40]. Kaufhold et al. used low doses of sugammadex to successfully reverse a moderate rocuronium-induced block. The reversal to TOF $>0.9$ was achieved with sugammadex at doses of 0.49 and $0.26 \mathrm{mg} / \mathrm{kg}$ within 5 and $10 \mathrm{~min}$ of its administration at TOF 0.2 [41]. Residual neuromuscular blockade at TOF 0.2 cannot be reliably reversed by neostigmine within 10 minutes. Doses of sugammadex significantly lower than the approved dose of $2.0 \mathrm{mg} / \mathrm{kg}$ may be sufficient under certain conditions to reverse the residual rocuronium-induced block when TOF $>0.2$ is recovered. Nevertheless, it seems that a slower reversal of curarisation may offset the benefits of using this modern drug compared to neostigmine. Special caution should be taken if lower doses of sugammadex are used to reduce the costs of anaesthesia. Quantitative monitoring is necessary throughout the treatment until the patient is discharged from the PACU.

Sugammadex used consistently with recommendations is a safe and effective drug to control residual curarisation and thus can prevent PPC $[42,43]$. Sugammadex is more effective than neostigmine and is associated with lower incidence of adverse effects $[42,43]$.

\section{Conclusions}


Nondepolarizing relaxants are safe in patients over 65 years of age if the neuromuscular blockade is monitored. Postoperative residual curarisation in elderly patients is a serious problem. It is the main cause of postoperative critical respiratory events, which may increase the mortality rate, time of hospitalization, and the cost of treatment.

Sugammadex provides effective protection against postoperative residual curarisation in patients older than 65 years and lowers the incidence of critical respiratory events in elderly patients. In a few years the price of sugammadex is expected to reduce, which will result in a complete departure from the use of neostigmine, mainly due to its side effects, long duration of action and low efficacy. Postoperative cognitive dysfunctions are inherently associated with ageing. Currently, there is no reliable and convincing evidence showing that fast and effective enhancement of neuromuscular endplate potential improves cognitive functions in elderly patients after general anaesthesia. There is a need to develop new drugs reversing the effects of neuromuscular blocking agents, both benzylisoquinolines and aminosteroids. Sugammadex has increased the safety of anaesthesia, and future studies are expected to show if this procedure can be made even safer.

\section{Abbreviations}

PACU - postanaesthesia care unit; PORC - postoperative residual curarisation; POCD - postoperative cognitive dysfunction; TOF - train of four; PPC - postoperative pulmonary complications; NMBD neuromuscular blocking drug, MMSE - Mini-Mental State Examination, FEV - Forced Expiratory Volume.

\section{Declarations}

All manuscripts must contain the following sections under the heading 'Declarations':

- Ethics approval and consent to participate:

The study protocol was approved by the Local Bioethical Committee of the Medical University in Lodz (RNN/704/10/KB). All patients gave written informed consent to participate in the study.

- Consent for publication

Not applicable

- Availability of data and materials

The datasets used and/or analysed during the current study are available from the corresponding author on reasonable request.

- Competing interests

The authors declare that they have no competing interests 
- Funding

Work performed with authors' own funds and Medical University of Lodz support - institutional funds for scientific work of the Department of Anaesthesiology and Intensive Therapy.

- Authors' contributions

TG projected the study. PP collected data, analyzed and interpreted the patient data, and was a major contributor in writing the manuscript. TG wrote, edited and corrected the manuscript. All authors read and approved the final manuscript.

- Acknowledgements

Not applicable.

- Authors' information

- Trial registration: ISRCTN registry - 37555; SYNABA-The Polish Clinical Trials Authorization, naukapolska.pl (ref. 252922), registered before first patient enrolment

\section{References}

1. Beecher HD, Todd DP: A study of deaths associated with anesthesia and surgery: based on a study of 599548 anesthesias in ten institutions. Ann Surg.1954; 4 - 26.

2. Pedersen T, Viby-Mogensen J, Ringsted C. Anaesthetic practice and postoperative pulmonary complications. Acta Anaesthesiol Scand.1992; 2 - 12.

3. Lunn JN, Hunter AR, Scott DB. Anaesthesia-related surgical mortality. Anaesthesia. 1983; 1091 1096.

4. Bainbridge et al. Perioperative and anaesthetic-related mortality in developed and developing countries: a systematic review and meta-analysis. Lancet. 2012; 1075 - 1079.

5. Naguib M, Brull SJ, Kopman AF, Hunter JM, Fülesdi B, Arkes HR, Elstein A, Todd MM, Johnson KB. Consensus Statement on Perioperative Use of Neuromuscular Monitoring. Anesth Analg. 2018 Jul;127(1):71-80. doi: 10.1213/ANE.0000000000002670.

6. Murphy, GS, Szokol, JW, Avram, MJ et al. Residual neuromuscular block in the elderly: incidence and clinical implications. Anesthesiology. 2015; 1325 - 1330.

7. Miskovic A, Lumb AB. Postoperative pulmonary complications. British Journal of Anaesthesia 2017; 118 (3): 317-334,

8. Kelkar VK. Post-operative pulmonary complications after non-cardiothoracic surgery. Indian J Anaesth 2015; 59(9): 599-605.

9. Fernandez-Bustamante A, Frendl G, Sprung J et al. Postoperative Pulmonary Complications, Early Mortality, and Hospital Stay Following Noncardiothoracic Surgery: A Multicenter Study by the 
Perioperative Research Network Investigators. JAMA Surg. 2017;152(2):157-166.

10. Pietraszewski P, Gaszyński T. Residual neuromuscular block in elderly patients after surgical procedures under general anaesthesia with rocuronium. Anaesthesiology Intensive Therapy. $2013 ; 77$ - 80.

11. Gaszyński T, Jakubiak J, Machała W. Występowanie resztkowego zwiotczenia u pacjentów z otyłością znacznego stopnia i jego wpływ na przebieg okresu pooperacyjnego - ocena obecnie stosowanej praktyki. Anestezjologia i Ratownictwo 2012; 67 - 73.

12. Billard C, Gehan G, Reboul- Marty J: Residual curarization in the recovery room after vecuronium. Br J Anaesth. 2000; 394 - 395.

13. Grosse-Sundrup, Henneman JP, Sandberg WS, Bateman BT, Uribe JV et al. Intermediate acting nondepolarizing neuromuscular blocking agent and risk of postoperative respiratory complications: prospective propensity score matched cohort study. BMJ 2012; 1 -14.

14. Naguib M, Kopman AF, Ensor JE. Neuromuscular monitoring and postoperative residual curarisation: a meta-analysis. Br J Anaesth. 2007;98(3):302-16.

15. Newman, SD;Stygall, J Hirani, S Shaefi S, Maze M; Postoperative cogintive dysfunction after noncardiac surgery: a systematic review. Anesthesiology 2007; 572 - 90.

16. Rasmussen, LS. Postoperative cognitive dysfunction: incidence and prevention. Best Practice \& Research Clinical Anaesthesiology. 2006; 315 - 330.

17. AARC Clinical Practice Guideline Spirometry. Update. Respiratory Care.1996; 629 - 636.

18. 18. Sauer M, Stahn A, Soltesz S, Noeldge-Schomburg G, Mencke T. The influence of residual neuromuscular block on the incidence of critical respiratory events. A randomised, prospective, placebo-controlled trial. Eur J Anaesthesiol. 2011;28(12):842-8.

19. Debaene B, Plaud B, Dilly MP, Donati F. Residual paralysis in the PACU after a single intubating dose of nondepolarizing muscle relaxant with an intermediate duration of action. Anesthesiology. 2003; 1042 - 1048.

20. Yip PC, Hannam JA, Cameron AJ, Campbell D. Incidence of residual neuromuscular blockade in a post-anaesthetic care unit. Anaesth Intensive Care. 2010; 91 - 95.

21. Frank Herbstreit, M.D.; Jürgen Peters, M.D.; Matthias Eikermann, M.D., Ph.D. Impaired upper airway integrity by residual neuromuscular blockade: increased airway collapsibility and blunted genioglossus muscle activity in response to negative pharyngeal pressure. Anesthesiology. 2009; 1253 - 1260.

22. Beblekos GD. Effects of laparoscopic cholecystectomy on lung function: a systematic review. World J Gastroenterol. 2014; 17603 - 17612.

23. Yang CK, Teng A, Lee DYPulmonary complications after major abdominal surgery: National Surgical Quality Improvement Program analysis. J Surg Res. 2015; 441 - 449.

24. Kor DJ, Warner DO, Alsara A Derivation and diagnostic accuracy of the surgical lung injury prediction model. Anesthesiology 2011; 117 - 128. 
25. McAlister FA, Bertsch $\mathrm{K}$ Incidence of and risk factors for pulmonary complications after nonthoracic surgery. Am J Respir Crit Care Med. 2005; 515 - 516.

26. Fisher BW, Majumdar SR Predicting pulmonary complications after nonthoracic surgery: a systematic review of blinded studies.. Am J Med. 2002; 219 - 225.

27. Lawrence VA, Hilsenberck SG Incidence and hospital stay for cardiac and pulmonary complications after abdominal surgery. J Gen Intern Med. 1995; 671 - 678.

28. Khan NA et al. Association of postoperative complications with hospital costs and length of stay in a tertiary care center. J. Gen Intern Med. 2006; 177 - 180.

29. Lewrence VA, Hilsenbeck, Novack Medical complications and outcomes after hip fractures reparil. Arch Intern Med. 2002; 2053 - 2057.

30. Khuri SF, Henderson WE, DePalma Determinants of long-term survival after major surge ry and the adverse effect of postoperative complications. Ann Surg. 2005; 326 - 341.

31. Nemes R, Fülesdi B, Pongrácz A, Asztalos L, Szabó-Maák Z, Lengyel S, Tassonyi E. Impact of reversal strategies on the incidence of postoperative residual paralysis after rocuronium relaxation without neuromuscular monitoring: A partially randomised placebo controlled trial. Eur J Anaesthesiol. 2017;34(9):609-616.

32. Groudine SB, Soto R, Lien C, Drover D, Roberts K. A randomized, dose-finding, phase II study of the selective relaxant binding drug, Sugammadex, capable of safely reversing profound rocuroniuminduced neuromuscular block. Anesth Analg. 2007; 555 - 562.

33. Hunter . Reversal of residual neuromuscular block: complications associated with perioperative management of muscle relaxation. British Journal of Anaesthesia. 2017; i54 - i62.

34. Martini CH, Boon M, Bevers RF, Aarts LP, Dahan A. Evaluation of surgical conditions during laparoscopic surgery in patients with moderate vs deep neuromuscular block. $\mathrm{Br} \mathrm{J}$ Anaesth. 2014; $498-55$.

35. Lee C, Jahr JS, Candiotti KA, Warriner B, Zornow MH, Naguib M.Reversal of profound neuromuscular block by sugammadex administered three minutes after rocuronium: a comparison with spontaneous recovery from succinylcholine. Anesthesiology. 2009; 1020 - 1025.

36. Cammu GV, Smet V, De Jongh K, Vandeput D. A prospective, observational study comparing postoperative residual curarisation and early adverse respiratory events in patients reversed with neostigmine or sugammadex or after apparent spontaneous recovery. Anaesth Intensive Care. 2012; $999-1006$.

37. Gaszynski T, Szewczyk T, Gaszynski W. Randomized comparison of sugammadex and neostigmine for reversal of rocuronium-induced muscle relaxation in morbidly obese undergoing general anaesthesia. Br J Anaesth. 2012; 236 - 239.

38. Kotake Y, Ochiai R, Suzuki T, Ogawa S, Takagi S, Ozaki M, Nakatsuka I, Takeda J.Reversal with sugammadex in the absence of monitoring did not preclude residual neuromuscular block. Anesth Analg. 2013; 345 - 351. 
39. Ledowski T, Falke L, Johnston F, Gillies E, Greenaway M, De Mel A, Tiong WS, Phillips M. Retrospective investigation of postoperative outcome after reversal of residual neuromuscular blockade: sugammadex, neostigmine or no reversal. Eur J Anaesthesiol. 2014; 423 - 9.

40. Schaller SJ, Fink H, Ulm K, Blobner M.Sugammadex and neostigmine dose-finding study for reversal of shallow residual neuromuscular block. Anesthesiology. 2010; 1054 - 60.

41. Kaufhold N, Schaller SJ, Stäuble CG, Baumüller E, Ulm K, Blobner M, Fink H.Sugammadex and neostigmine dose-finding study for reversal of residual neuromuscular block at a train-of-four ratio of 0.2. Br J Anaesth. 2016; $233-240$.

42. Carron M, Zarantonello F, Tellaroli P, Ori C. Efficacy and safety of sugammadex compared to neostigmine for reversal of neuromuscular blockade: a meta-analysis of randomized controlled trials. J Clin Anesth. 2016;35:1-12.

43. Hristovska AM, Duch $P$, Allingstrup M, Afshari A. Efficacy and safety of sugammadex versus neostigmine in reversing neuromuscular blockade in adults. Cochrane Database Syst Rev. 2017; 14(8):CD012763.

44. Brueckmann B, Sasaki N, Grobara P, LiMK, Woo T, de Bie J, Maktabi M, Lee J , Kwo J, Pino R, Sabouri AS, McGovern F, Staehr- Rye AK, Eikermann M. Effect of sugammadex om incidence of postoperative residual neuromuscular blockade: a randomized, controlled study. Br J Anaesth. 2015; $743-51$. 